\title{
The Application and Importance of Marketing and its Tools in the Conditions of Non-profit Organizations on a Global Scale
}

\author{
Zuzana Rosnerova ${ }^{1, *}$, and Dagmar Hraskova ${ }^{2}$ \\ ${ }^{1}$ University of Zilina, Faculty of Operation and Economics of Transport and Communications, \\ Department of Economics, Univerzitna 1, 01026 Zilina, Slovakia
}

\begin{abstract}
.
Research background: Marketing as a separate area of activities does not immediately occur only in the environment of companies, but is also used in the environment of non-profit organizations. Although the activities of non-profit organizations differ significantly from the activities of commercially oriented companies, even in the case of non-profit organizations, marketing activities and tools are used to improve the overall progress of non-profit organizations.

Purpose of the article: The article deals with the analysis of marketing activities and tools that are applied in the conditions of non-profit organizations. In the case of applicable marketing tools, we will also address the question of whether it is necessary to modify traditional marketing tools in the environment of non-profit organizations. The aim of the article is to analyse the most frequently applied marketing tools in the environment of non-profit organizations.

Methods: Descriptive methods as well as comparative methods are used in the analysis in order to compare them with the commercial sector. In this article, we work with the hypothesis that the application of the marketing concept will be different compared to profit-oriented marketing and we assume that marketing strategies will require a certain degree of modification.

Findings \& Value added: Based on the performed analysis, we will evaluate the findings of this issue and suggest other options for the implementation of marketing tools in the environment of non-profit organizations.
\end{abstract}

Keywords: marketing of non-profit organizations, marketing tools, marketing plan, marketing strategy

JEL Classification: $M 31 ; L 30 ; F 60$

\footnotetext{
*Corresponding author: zuzana.rosnerova@fpedas.uniza.sk
} 


\section{Introduction}

The term marketing is currently one of the terms that we encounter quite often in common practice. The theory of marketing is defined through various variations from different authors, but the most commonly inflected and best-known definition is from the author Kotler, who defines marketing as a social and managerial process, based on which individuals or groups are able to meet their needs [1]. Marketing in today's global environment is based on the fact that a strong emphasis is placed on satisfying customer requirements [2]. We find an identity with this statement with the definition of the author Johnova, which specifies the marketing goal so that the basis is to deliver the right product to the right customer, in the right place, at the desired price and with a reasonable level of promotion, which is ultimately better than promotion to competitors. According to her, the precondition for the success of any organization depends on how the organization can know its customer and his needs and how he can adapt to them [3]. The goal of marketing can therefore be specified as an effort to get to know the customer perfectly, to analyse his needs and wishes [4].

Marketing applied in the corporate environment and marketing carried out in the case of non-profit entities will show some differences compared to commercial marketing. The most striking difference will be the price factor, as non-profit organizations work in the non-profit sector and their goal is not to make a profit. Thus, compared to commercial enterprises, profit is not the primary goal of a non-profit organization [5]. The establishment of non-profit entities is directly linked to their mission and their basic goal is to provide public benefit services. The purpose of non-profit entities is to assist in areas that are not covered by the state [6]. Areas of operation of non-profit entities include: provision of health care, provision of humanitarian aid, provision of services in the field of education, culture, sports or environmental protection or provision of social services. The services provided by these entities are provided without the right to payment, i.e. free of charge [7]. In some countries, non-profit organizations and their contribution to society are highly praised, e.g. in Australia [8].

Within the price area, we thus encounter a basic difference in the comparison of the forprofit and non-profit spheres for marketing implementation. At present, there is strong scientific and technical progress, which has not been bypassed even in the field of marketing [9]. Through communication, the entity informs the target audience about its scope and from the level of communication also depends the progress and the stability of the market position in the market [10].

Marketing communication has been significantly affected by the time of digitization, offering marketers a much easier way to obtain information on the needs of target customers as well as to inform customers about their services or products [11]. However, the creation of a marketing concept is not free and in the case of non-profit organizations it is necessary to significantly supervise the financial possibilities. As we have to take into account the non-profit aspect of this type of entity, which is related to their existence, the possibilities for financing the field of marketing are thus limited [12]. Due to the nature of non-profit, many non-profit organizations are unable to develop marketing, which stems from individual financial possibilities [13]. On the other hand, marketing in the environment of non-profit organizations is an appropriate tool through which non-profit organizations can increase their self-cognizance in the community, attract donors or volunteers and is a means to achieve better results in terms of growth and fulfilment of their mission [14]. 
Non-profit marketing is a set of practices and strategies that can be used in this type of organization to strengthen the goals of the organization, its mission, expand the circle of donors, obtain more funding and, last but not least, attract volunteers to work for nonprofits [15]. The application of the marketing concept is limited in the case of non-profit organizations due to the fact that these entities do not have to achieve profit as their primary element. As a result, the resources of non-profit entities are limited and the possibilities of implementing marketing strategies are thus tied to the financial possibilities of the organization [16].

Although non-profit organizations are not established for the purpose of reporting a profit, in practice it may happen that a profit can be achieved. In such a case, however, the profit obtained can be spent exclusively on financing the needs of the organization, its activities and not on the distribution among the founders of the non-profit organization. Non-profit financial results are very closely linked to marketing, as organizations rely on collecting contributions from their donors and the only way to attract and reach the widest possible range of donors is through communication with the outside environment and communication in various forms is part of marketing tools [6].

As for the ways of marketing communication, there are several possible forms through which organizations can communicate with the outside environment. However, attention is paid to the fact that the non-profit organization chooses the appropriate marketing tools, which it will be able to cover financially [17].

In this article, we focus on the specification of such marketing tools that are commonly available and, on the other hand, can be implemented by non-profit organizations without the need to spend a large amount of funds. The article uses descriptive and comparative methods for the researched issues. We work with the hypothesis that the application of the marketing concept will be different from profit-oriented marketing, and we assume that marketing strategies will require a certain degree of modification.

\section{Methods}

Non-profit marketing is a means for a non-profit organization through which it can spread awareness about itself among the public. The brand in this case is the non-profit organization itself. In particular, because the brand is essentially a non-profit organization itself, it must make a great effort to promote itself, disseminate information about itself and also consider the overall opportunities offered to it in the market.

An important issue for non-profit organizations is their financing. In many cases, this is a real obstacle for non-profit entities, as they rely on obtaining resources from the external environment. If a non-profit organization is not able to spread information about itself and raise awareness, then it is likely that more significant problems may arise in the case of its funding. On the contrary, if a non-profit organization succeeds in spreading awareness about itself, attracting new people to itself, reaching as many potential donors as possible, then the success of the non-profit organization in the market is likely. Non-profit marketing in this type of organization thus provides support for donor membership and leads to the fact that donors can repeatedly contribute funding for the operation of a non-profit entity. In this case, it is also important to promote how donors can constantly contribute and thus support a non-profit entity.

Through non-profit marketing, new people enter the organization, volunteers who will work in the non-profit organization. Regardless of the area in which the non-profit entity operates and what its size is, each non-profit entity benefits from the implementation of non-profit marketing. Through non-profit marketing, not only the organization itself is promoted, but its services are also promoted. In the case of a non-profit entity, we work with the three strongest pillars, on which its overall success and existence on the market 
depend. These include awareness, funding and volunteers, and these three elements form the mainstay of any non-profit entity. In this case, the creation of a non-profit marketing plan is justified. The marketing plan that can be implemented in non-profit organizations does not have to differ much from the plan that is used in the private sector, which is primarily profit-oriented. However, for non-profit organizations, the marketing plan must be created with more emphasis, because it is very important for the non-profit organization. Implementing a marketing plan in the practice of non-profit organizations allows to focus on raising awareness of their mission and their better functioning. The creation of a marketing plan should proceed as follows, according to the following sequence:

1. Setting marketing goals: Through a non-profit plan, it is thus possible to ensure the transformation of the mission of a non-profit organization and its goals into strategic goals that are at the same time feasible by the given non-profit organization. Marketing aimed at achieving the set goals of a non-profit organization can be applied e.g. by publishing up-todate information on social networks in order to maximize the dissemination of information. When setting goals, it is also very important in the environment of non-profit organizations, as is the case with companies, to monitor and respect the SMART rule. This means that the non-profit organization's objective thus specified must meet certain attributes, which include:

$\mathrm{S}$ - SPECIFIC - the objective must be clearly specified,

M - MEASURABLE - must be measurable,

A - ACHIEVABLE - must be achievable,

$\mathrm{R}$ - REALISTIC - must be realistic resp. relevant,

$\mathrm{T}$ - TIME SPECIFIC - must be timed. below.

Examples of how a non-profit should proceed when setting goals are given in the Table

Table 1. Examples of attributes that must be met when setting goals

in non - profit organizations

\begin{tabular}{|c|l|}
\hline $\mathrm{S}$ & Training volunteers 4 times a year \\
\hline $\mathrm{M}$ & Increase of website traffic on social networks by $15 \%$. \\
\hline $\mathrm{A}$ & $\begin{array}{l}\text { Visit rate to the site on social networks increased by } 10 \% \text { in the past } \\
\text { period. We could achieve a } 15 \% \text { increase in traffic this year. }\end{array}$ \\
\hline $\mathrm{R}$ & $\begin{array}{l}\text { Dissemination of information about the organization through social } \\
\text { networks will increase awareness in the eyes of the public about our } \\
\text { mission, draw more people's attention to our services, the possibilities } \\
\text { of their use, reach more donors and thus bring funds to the } \\
\text { organization. }\end{array}$ \\
\hline $\mathrm{T}$ & $\begin{array}{l}\text { We will start adding a post to social networks once a week starting } \\
\text { next week. }\end{array}$ \\
\hline
\end{tabular}

The legitimacy of using goals that meet the SMART rule is important especially if we want to analyse and measure the marketing performance of a particular non-profit organization. Otherwise, it is not possible to perform such an analysis.

2. Getting to know your audience: Non-profit marketing is much more complex compared to business marketing. Its complexity stems mainly from the fact that non-profit marketing is focused on several groups. They are target customers, volunteers and donors, while the company focuses exclusively on the end customer in its marketing. Differences will be present e.g. also within the communication between the non-profit organization and a specific group, the audience. Otherwise, the non-profit organization will communicate in 
the case of donors, differently in the case of volunteers and differently in the case of customers. For each type of communication, the non-profit organization must choose the most appropriate content so that it does not fail in the event of an effort to strengthen the entire functioning of the non-profit organization.

3. Creating key reports: The key reports contain all the information that should be communicated to the non-profit audience. It's important that information for your target audience is easy to remember. Even with key messages, it is important to follow a certain rule, and that is the consistency of the messages. This means that no matter who creates and distributes the messages, the messages should be identical, that is, they should promote the same in terms of content. Key messages help to select and properly organize the various pubs. The development of key messages for each audience informs the field of marketing, so that it is then possible to find out what the response of the key messages is for the given audience. In the case of interconnection with the mission, vision and goals of a non-profit organization, key messages help to communicate effectively outwards.

4. Choosing, planning and choosing the right marketing strategy: In the case of a marketing strategy, a non-profit organization addresses the question of how it is possible to acquaint the audience with the information? The marketing strategy is linked to email marketing, social media or various events, etc. As part of the solution of the marketing strategy, it is necessary to plan the selected strategy appropriately and during its preparation it is important to monitor the following issues:

- What will we achieve through the chosen marketing strategy?

- When will the marketing activities take place?

- What is the importance of the chosen tactic?

- Who will be responsible for carrying out the activities?

- How much money will it cost?

- How does the tactic relate to the marketing goals of the non-profit organization?

This strategic planning is an integral part of a non-profit marketing plan. It is also important how marketing strategies are approached, what impact they bring to the nonprofit organization and how they are implemented.

5. Analysis of marketing strategy: As in the case of corporate entities, as well as in the case of non-profit organizations, the beginnings of marketing are more difficult and its performance often does not meet high values. Through routine reports, the non-profit organization is able to analyse weaknesses and thus be able to find out what works in marketing and what, on the contrary, needs to be changed. In this area, it is justified when the entity will monitor the measurable performance of individual elements. The following figure is given as an example.

\begin{tabular}{|c|c|}
\hline Marketing Strategy & Performance indicator \\
\hline E-mail marketing & Email opens \\
\hline Event marketing & Ticket sales \\
\hline Video marketing & Video views \\
\hline Social nets & Shares and comments \\
\hline Website & Page views \\
\hline Public speaking & Referrals \\
\hline Content marketing & Subscriptions \\
\hline
\end{tabular}

Fig. 1. Marketing strategies and relevant indicators for measuring their performance 
If a non-profit organization knows in advance which indicators it wants to measure first, it will also know exactly what it will be necessary to focus on.

The strategies that can be applied in the environment of non-profit organizations are shown in Figure 1. The basis for the application of marketing strategies is the creation of a marketing team that would be in charge of solving the entire area of marketing. Due to the nature of non-profit organizations, we must take into account that the marketing team will consist of only a few people, as opposed to talking about a marketing team that will work for the company. The company employs marketing teams composed of several people, which is not possible in the case of non-profit organizations due to limited financial resources. In some cases, if the financial situation of the non-profit organization allows, it is also possible to use outsourcing to solve the marketing concept.

\section{Results and discussion}

This part of the article deals with the issue of marketing strategies that can be used in the marketing concept in the environment of non-profit organizations. It analyses specific strategies and describes specific tools that a non-profit organization can use to achieve its stated goals and obtain benefits through these tools. The aim of the analysis of marketing strategies for application in non-profit organizations was to point out the possibilities that can be used to spread awareness or attract volunteers, donors, etc.

1. Email marketing: this way of communicating with the target audience can be considered very effective in terms of reaching people. The way in which a non-profit organization can fulfil its intended goals is e.g. addressing through weekly newsletters containing the latest content, the latest information or news related to recruiting volunteers. In the case of solving the issue of donation, the frequency of contacting potential donors once a month through this type of communication can be. It is also very important to link the website with email communication, e.g. so that the website offers its visitor the opportunity to subscribe to the newsletter by e-mail. The level of automation is important in this strategy. For the best possible result, non-profit organizations are recommended a high degree of automation of e-mail marketing, which will also save time for the marketing team and will also offer the possibility of expanding the e-mail list or donors.

2. Event marketing: It is one of the most effective ways to raise awareness of the mission and activities of a non-profit organization, to obtain funding, and in general to determine the level of support for a given non-profit organization. As an example, we could cite various charitable events, e.g. a charity run to which an unlimited number of people can be added to raise funds to promote the "good cause", or various competitions or auctions can take place.

3. Video marketing: Currently, visual content as such is in high demand. People are watching in a big video and there is also room for a non-profit organization. We recommend visual content mainly because when a respondent sees a campaign via video, he or she can remember it much better in terms of content, which is more effective and longer than in the case of written content. The advantage of video content is that it can incorporate elements that attract people and leave a certain impression, emotions. Such targeted content can not only attract potential volunteers, but can also appeal to potential donors who ultimately decide to financially support a non-profit organization. A very big advantage in today's visual environment is that videos can be shared and distributed in this way. 
4. Social medias: Social networks are very popular today from a global perspective. Even in the case of non-profit entities, social networks are a popular marketing strategy. The big benefit is that social networks offer account opening for virtually free of charge and through which it is possible to connect with the whole world. In order to be successful, emphasis should be placed on constantly adding news, updates to social networks, adding videos, so that respondents or supporters are as interested in the content as possible and so that it can attract them at all. It is appropriate to share reports about its non-profit organization and its activities, as well as to raise awareness about the non-profit organization, it is also very important to thank the employees, donors and volunteers who help the non-profit organization and its functioning in the market.

5. Website: In order to function effectively, each non-profit organization should have its own website. Through the website, the non-profit organization can also communicate with its audience, and this medium should also contain current information, news and should be regularly updated. The website should contain everything related to the activity of a non-profit organization, e.g. blogs, videos, event information, photo archive, streams, which can also be published via social media and the like. In essence, through a website, a non-profit organization can address its audience and attract or inspire it - e.g. if we take into account potential volunteers.

6. Public speaking: Public speaking is a very effective way for people to get to know the team that runs a non-profit, get acquainted with all the activities they do to make a nonprofit work, and try to advance and fulfill its mission. Every non-profit organization has a story that can engage people, and it is through this tool that there is a good opportunity to impress others and acquaint them with how they can get involved in and support a nonprofit organization, always presenting purpose as well as the brand - i.e. the non-profit organization itself.

7. Content marketing: Depending on the content, information and marketing of the non-profit organization, it will also reflect the interest of the audience in its activities. Through the content, the non-profit organization informs people, attracts donors, volunteers or new visitors to the events. In terms of today's possibilities, the content can be shared through various media and basically serves as free public relations. The only problem may be preparing content through marketing teams, which often consist of only a small number of members. Another obstacle is limited finances as well as time. In this case, it is possible to work with volunteers or employees who can bring new ideas to marketing, especially in terms of knowing exactly where there are potential gaps and what could be improved.

Thus, non-profit marketing can ensure the inflow of funds into the organization through a well-designed marketing concept, which will then be implemented in practice. Through marketing, a non-profit organization can reach a wide range of donors, who may eventually choose to support the activities of a non-profit organization. Of course, at the beginning of the solution of the marketing concept it is necessary to spend a considerable amount of money to start enlightenment, but in the end, when marketing activities prove themselves and prove beneficial, the non-profit organization will achieve far better effects in its financial performance. On the other hand, marketing does not only have to be an inflow of funds, but it can also reach people whose activities and focus can appeal so much that they want to become volunteers and help with their own contribution to fulfil the mission of a non-profit organization. In this case, marketing can be understood as a means for the influx of volunteers into a non-profit organization.

In order for a non-profit organization to function effectively, it should take into account certain steps and sequences in the implementation of the marketing concept in order to be able to bring the most effective result in the target market. In order to function effectively, a 
non-profit organization must constantly take into account its responsibility to society [18]. In the case of non-profit organizations, we can also talk about innovation in the internal environment. Process innovation is important not only for companies, but also for nonprofit organizations, and in the field of marketing it is also possible to monitor and implement changes that are desirable for the effective operation of a non-profit organization [19].

The hypothesis we worked with in the article was partially confirmed. As for the marketing strategies applied in non-profit organizations, they are not fundamentally different from the strategies used by commercially oriented companies. There are changes in the tools that are used in individual strategies and must be modified due to the nature of non-profit organizations and their primary goal.

\section{Conclusion}

In the case of non-profit organizations, marketing is a necessity in the issue of raising awareness and disseminating information about the organization. Marketing activities aimed at building awareness of a non-profit organization are a very valuable tool on the basis of which a non-profit entity can raise significantly more resources compared to a situation where marketing activities would be neglected and not paid attention to. In practice, the more people and thus potential donors learn about the activities and activities of a non-profit organization, the more funds the entity can obtain. Thanks to the marketing of a non-profit organization, the mission of the organization gets to people's awareness faster and informs them about how they can become donors and thus contribute to the good cause. Another positive that non-profit marketing brings is the recruitment of volunteers for their non-profit organization, especially by disseminating information to the public.

The key to the success of a non-profit entity in the market is the constant dissemination of information about itself, while the principle of uniform content must be respected. The advantage is that it is possible to use several tools at once, which can overlap each other, but it is always necessary to strictly adhere to the content of the information provided.

The paper is an output of the science project VEGA 1/0544/19 Formation of the methodological platform to measure and assess the effectiveness and financial status of non-profit organizations in the Slovak Republic.

\section{References}

1. Kotler, P., et al. (2007). Moderni marketing. Praha: Grada Publishing.

2. Krizanova, A., Gajanova, L., Nadanyiova, M. (2019). Design of a CRM level and performance measurement model. Sustainability, 10(7), 2567.

3. Johnova, R. (2011). Marketing kulturniho dedictvi a umeni: Art marketing v praxi. Praha: Grada Publishing.

4. Karlicek, M. (2018). Zaklady marketingu. Praha: Grada.

5. Crotty, J., Ljubownikow, S. (2019). Restrictive Institutions and Critical Resources: Non-Profit Organisations and Volunteer Resources in the Russian Federation. EuropeAsia Studies, 72(1), 99-116.

6. Majduchova, H. (2009). Non-profit organizations. Bratislava: Sprint dva.

7. Jiang, L. (2018). Research on Accounting System of Government and Non-profit Organizations, In: Jing, W., Ning, X., Huiyu, Z. (Eds.), Proceedings of the 8th 
International Conference on Management and Computer Science. (pp. 109-112). Nanchang: Atlantis Press.

8. Lyons, M., North-Samardzic, A., Young, A. (2007). Capital Access of Nonprofit Organisations. Agenda, 14(2), 99-110.

9. Karaaslan, O. (2017). Leaders' language use and perceived trust in leader: a quantitative study in an international central european non-profit organization. Forum Scientiae Oeconomia, 5(3), 101-119.

10. Vrtana, D., Krizanova, A. (2018). Brand Strategy of Successful Companies.In: Soliman, K.S (Eds.), Sustainable Economic Development and Application of Innovation Management, (8007-8014). Seville: Proceedings Paper.

11. Udell, M. Stehel, V., Kliestik, T., Kliestikova, J., Durana, P. (2019). Towards a smart automated society: cognitive technologies, knowledge production, and economic growth. Economics, management, and financial markets, 14(1), 44-49.

12. Shemyatikhina, L., Shipitsyna, K., Usheva, M. (2020). Marketing management of a non-profit organization. Ekonomicko-manazerske spektrum, 14(1), 19-29.

13. Bacuvcik, R. (2012). Marketing Kultury: Divadlo, koncerty, publikum, verejnosti. Zlín: Verbum.

14. Andjarwati, T., Susilo, K. E., Audah, A. K. (2019). Predictors of job satisfaction in non-profit organizations. Polish Journal of Management Studies, 20(1), 19-28.

15. Popoola, O., Alege, P.O., Gershon, O. Asaleye, J.A. (2019). Human capital channels and productivity growth: Evidence from Nigeria. Economics and Sociology, 12(4), 5973.

16. Valaskova, K., Kliestikova, J., Krizanova, A. (2018). Consumer Perception of Private Label Products: An Empirical Research. Journal of Competitiveness, 10(3), 149-163.

17. Turrini, L., Besiou M., Papies D. (2019). The role of operational expenditures and misalignments in fundraising for international humanitarian aid. Retrieved from: https://onlinelibrary.wiley.com/doi/full/10.1002/joom.1072.

18. Carvalho, A. O., Ferreira, M. R., Silva, P. A. (2019). Partners in a caring society - a nonprofit organization case study. Economics and Sociology, 12(2), 129-146.

19. Sahban, M. A. (2019). The transformational leadership, knowledge management and perceived organizational support in predicting innovation capability. Polish Journal of Management Studies, 20(1), 372-381. 